\title{
Analisis Tarif Pajak Progresif Kendaraan Bermotor \\ Berdasarkan The Four Maxims Di Upt \\ Bp2rd Provsu Stabat
}

\author{
Putri Kemala Dewi Lubis. ${ }^{1}$ \\ Universitas Negeri Medan \\ putrikemala@unimed.ac.id ${ }^{1}$
}

Penelitian ini bertujuan untuk mengetahui penerapan tarif pajak progresif pada pajak kendaraan bermotor berdasarkan The Four Maxims Di UPT BP2RD PROVSU Stabat. Pendekatan penelitian yang digunakan adalah pendekatan deskriptif, menggunakan data kuantitatif berupa datadata jumlah penerimaan pajak kendraan bermotor dan penerimaan pajak progresif serta sumber data primer berupa wawancara dan data sekunder yang dikumpulkan dari laporan-laporan realisasi penerimaan pajak progresif dan Pendapatan Asli Daerah (PAD) pada UPT BP2RD PROVSU Stabat.

Hasil penelitian menunjukkan berdasarkan asas equality (asas keadilan), pengenaan tarif pajak progresif pada Pajak Kendaraan Bermotor sangat adil karena pembebanan pajak harus sesuai dengan kemampuan wajib pajak. Berdasarkan asas certainly (asas kepastian hukum), dasar pengenaan Pajak Kendaraan Bermotor sangat jelas sesuai dengan pengenaan tarif pajak progresif pada pajak kendaraan bermotor dipungut berdasarkan Peraturan Gubernur Sumatera Utara No. 37 Tahun 2015. Berdasarkan asas Conveinance of payment (asas ketepatan waktu dalam membayar pajak) pembayaran pajak kendaraan bermotor UPTD melaksanakan pemungutan pajak sesuai dengan tanggal habis masa berlaku pajak kendaraan bermotor. Berdasarkan asas efisiensi pengenaan tarif pajak progresif pada kendaraan bermotor melalui pelayanan pemungutan pajak dan informasi pemungutan pajak yang sangat jelas dan cukup baik, UPT BP2RD PROVSU Stabat berusaha terjun langsung ke masyarakat melalui camat atau lurah dengan menggunakan fasilitas-fasilitas yang ada dan berusaha untuk mencapai pendapatan pajak melebihi target yang telah ditetapkan.

Kata Kunci : Pajak Progresif, Pajak Kendaraan Bermotor, The Four Maxims. 


\section{Pendahuluan}

Peningkatan jumlah kendaraan bermotor akan menimbulkan banyak permasalahan salah satunya masalah kemacetan yang hampir terjadi di seluruh jalan. Salah satu upaya untuk mengendalikan jumlah kendaraan bermotor perlu adanya ketentuan yang baru mengenai pajak kendaraan bermotor. Pajak kendaraan bermotor adalah pajak atas kepemilikan atau penguasaan kendaraan bermotor, sesuai dengan Undang-Undang Republik Indonesia Nomor 28 Tahun 2009 tentang pajak daerah dan retribusi daerah. Pajak kendaraan bermotor merupakan jenis pajak yang kewenangannya ada pada provinsi yang menjadi primadona dalam sumbangsih terhadap penerimaan dalam kas daerah yang dapat menambah serta menunjang pemasukan anggaran rumah tangga daerah. Hampir setiap aktivitas pekerjaan yang dilakukan tidak luput dari penggunaan kendaraan bermotor menjadi primadona dalam memberikan pemasukan pendapatan yang lebih besar daripada jenis-jenis pajak daerah lainnya.

Sesuai dengan Peraturan Daerah Provinsi Sumatera Utara Nomor 1 Tahun 2015, besarnya tarif pajak progresif kendaraan bermotor roda dua dan roda tiga berbeda dengan tarif pajak progresif untuk kendaraan bermotor roda empat. Untuk kendaraan bermotor roda dua dan roda tiga besarnya tarif progresifnya untuk kepemilikan kedua sebesar 2\%; kepemilikan ke tiga sebesar 2,5\%; kepemilikan keempat sebesar 3\%; kepemilikan kelima dan seterusnya sebesar 3,5\%. sedangkan untuk kendaraan bermotor roda empat besar tarif progresifnya untuk kepemilikan kedua sebesar 2,5\%; kepemib likan ketiga sebesar 3\%; kepemilikan keempat sebesar 3,5\%; kepemilikan kelima dan seterusnya sebesar 4\%.

Berlakunya tarif pajak progresif atas kendaraan bermotor menimbulkan dampak bagi masyarakat, baik itu dampak positif maupun dampak negatif. Dampak positif dari berlakunya pajak progresif kendaraan bermotor yaitu berkurangnya jumlah kendaraan bermotor. Sedangkan bagi pemerintah daerah, dengan berlakuknya pajak progresif untuk kendaraan bermotor menyebabkan bertambahnya jumlah pendapatan daerah dari sektor pajak daerah. Dampak negatif yang terjadi di masyarakat yaitu sebagai wajib pajak melakukan penyeludupan hukum untuk menghindari pembayaran pajak kendaraan bermotor yang lebih besar (Nugraha, 2012).

Penerapan tarif pajak progresif diyakini mampu menjadi bagian dalam mengendalikan jumlah kendaraan di Kota Stabat. Selain itu juga dapat meningkatkan Pendapatan Asli Daerah di Kota Stabat, karena dengan meningkatnya jumlah pajak yang harus dibayarkan oleh wajib pajak tentu saja akan berpengaruh terhadap PAD di Kota Stabat.

Asas pemungutan perpajakan berdasarkan The Four Maxims yang dikemukanan oleh Adam Smith dijalankan dengan empat asas yaitu, asas keadilan (equality), asas kepastian hukum (certainly), asas tepat waktu (conveinance of payment), dan asas ekonomi (economy). Asas keadilan (equality) tarif pajak pajak progresif pajak kendaraan bermotor (PKB) adalah yang terbaik. Asas keadilan (equality) menentukan bahwa seseorang yang kemampuan membayarnya lebih tinggi harus membayar pajak yang lebih besar pula. Asas kepastian hukum (certainly) masih terdapat kendaraan bermotor yang berganti kepemilikan dan wajib pajak tidak mengajukan permohonan pembekuan kendaraan bermotor maka dikenakan pajak sesuai ketentuan peraturan perundang-undangan. Asas tepat waktu (conveinance of payment) menentukan bahwa pemungutan pajak harus dilaksanakan pada waktu yang tepat, dimana wajib pajak tidak keberatan atau kesulitan saat membayar tanggungan pajaknya. Tetapi masih terdapat banyak pajak kendaraan yang menunggak dan masyarakat menunda-nunda untuk membayar pajak kendaraan yang sengaja menunggu pemutihan pajak agar lebih ringan membayar pajak kendaraannya. Asas efisiensi (efficiency) pelaksanaan pemungutan pajak harus dilakukan secara efisien. Hal ini menunjukkan bahwa dengan biaya pemungutan yang kecil dibandingkan dengan proporsional dengan peningkatan penerimaan dapat menghindarkan penyimpangan perilaku wajib pajak (Diana, hal 59).

\section{Rumusan Masalah}

Rumusan masalah dalam penelitian ini yaitu:

1. Bagaimana penerapan tarif pajak progresif pada pajak kendaraan bermotor berdasarkan The Four Maxims di UPT BP2RD PROVSU Stabat?

2. Upaya apa yang dilakukan oleh petugas BP2RD PROVSU Stabat dalam meningkatkan penerimaan pajak kendaraan? 


\section{LANDASAN TEORI}

\section{Pengertian Pajak Kendaraan Bermotor}

Menurut Peraturan Daerah (PERDA) Nomor 1 Tahun 2011 Tentang Pajak Daerah Provinsi Sumatera Utara yaitu Pajak Kendaraan Bermotor adalah pajak atas kepemilikan dan atau penguasaan kendaraan bermotor, yaitu kendaraan beroda dua atau lebih beserta gandengannya yang digunakan di semua jenis jalan darat dan digerakkan oleh peralatan teknik berupa motor atau peralatan lainnya yang berfungsi untuk mengubah sumber daya energi tertentu menjadi tenaga gerak kendaraan bermotor yang bersangkutan, termasuk alat-alat besar yang dalam operasinya menggunakan roda dan motor dan tidak melekat secara permanen serta kendaraan bermotor yang dioperasikan di air.

Pajak kendaraan bermotor menurut pasal 1 ayat 12 Undang-Undang Nomor 28 Tahun 2009 tentang Pajak Daerah dan Retribusi Daerah adalah pajak atas kepemilikan dan/atau penguasaan kendaraan bermotor. Pajak kendaraan bermotor yang bersifat objektif tergantung pada objek yang dikenakan pajak dan berada dalam kepemilikan dan/atau penguasaan wajib pajak.

\section{Subjek Pajak Kendaraan Bermotor}

Menurut Undang-Undang Nomor 28 Tahun 2009, subjek pajak kendaraan bermotor adalah orang pribadi atau badan yang memiliki dan atau menguasai kendaraan bermotor. Dengan demikian, subjek pajak kendaraan bermotor sama dengan wajib pajak kendaraan bermotor, yaitu orang atau badan yang memiliki atau menguasai kendaraan bermotor.

\section{Objek Pajak Kendaraan Bermotor}

Objek pajak kendaraan bermotor adalah kepemilikan dan atau penguasaan kendaraan bermotor. Objek pajak yang dimaksud adalah sebagai berikut:

1. Kendaraan bermotor yang digerakkan oleh motor, yang dihidupkan dengan generator, gas arang atau oleh motor yang memakai bahan bakar minyak tanah atau campuran minyak tanah dan bensin, terlepas dari hal apakah motor itu khusus atau tidak khusus diperuntukkan menggunakan minyak tanah atau dengan campuran minyak tanah dan bensin

2. Segala kendaraan bermotor lainyya yang tidak digerakkan oleh motor yang semata-mata menggunakan bensin sebagai bahan bakar.

3. Kendaraan bermotor, yang digerakkan oleh moto dengan semata-mata menggunakan Bensin sebagai bahan bakar, yang mempunyai berat total yang diizinkan $3.500 \mathrm{~kg}$ atau lebih.

4. Kereta tambahan (kereta gandengan) dari kendaraan bermotor (wagon trailers).

5. Kendaraan bermotor seperti yang dimaksudkan pada huruf $\mathrm{C}$ yang mempunyai berat total yang diperkenankan kurang dari $3.500 \mathrm{~kg}$, kecuali yang telah dikenakan Pajak Rumah Tangga berdasarkan Pasal 11 Ayat (4) dan (6).

\section{Asas The Four Maxims}

Diana (2013, hal 59) menyatakan bahwa asas pemungutan perpajakan berdasarkan The Four Maxims yang dikemukanan oleh Adam Smith dijalankan dengan 4 asas yaitu:

1. Asas Equality ( asas keadilan)

Asas ini menyangkut keadilan pendistribusian pajak dari berbagai kalangan, yang mengandung arti bahwa setiap orang yang berada dalam keadaan yang sama harus dikenakan pajak yang sama. Ini tidak berarti bahwa setiap orang (warga negara) dikenakan pajak yang sama. Walaupun penghasilannya sama tetapi setiap orang yang mempunyai penghasilan kena pajak yang sama akan dikenakan pajak yang sama.

2. Asas Cerrainly (asas kepastian hukum)

Asas ini mengenai tidak terdapatnya kesewenangan dan ketidakpastian berkenaan dengan utang pajak, yang mengandung pengertian bahwa pajak yang harus dibayar oleh masing-masing wajib pajak harus bersifat pasti, jelas dan tidak bersifat sewenang-wenang. Artinya bagi si wajib pajak harus ada kepastian yang jelas, tegas untuk dijadikan pegangan yang memungkinkan mengenai bentuk, subjek, objek, jenis, tarif berdasarkan undang-undang yang berlaku. 
3. Asas Conveinence of payment (asas tepat waktu)

Asas ini menyagkut cara pembayaran pajak, yang mengandung pengertian bahwa pajak harus dipungut pada saat yang tepat, yaitu saat yang paling memudahkan dan menyenangkan bagi wajib pajak untuk membayarnya.

4. Asas Efficiency ( asas efisien)

Secara ekonomi bahwa biaya pemungutan dan pemenuhan kewajiban pajak bagi wajib pajak diharapkan seminimum mungkin, demikian pula beban yang ditanggung wajib pajak. Dengan biaya pemungutan yang kecil dibandingkan dengan proporsional dengan peningkatan penerimaan dapat menghindarkan penyimpangan perilaku wajib pajak.

\section{Tarif Pajak Progresif Kendaraan Bermotor}

Tarif pajak progresif kendaraan bermotor adalah persentase tarif yang digunakan yang semakin besar bila jumlah objek yang dikenai pajak semakin banyak.Untuk besaran tarif pajak progresif pada kendaraan bermotor diatur dalam Peraturan Gubernur Sumatera Utara No. 37 Tahun 2015 tentang Pelaksanaan Pemungutan Pajak Kendaraan Bermotor dan Bea Balik Nama Kendaraan Bermotor Di Provinsi Sumatera Utara pasal 11 ayat (4) dan (5) dengan besaran tarif progresif untuk kendaraan bermotor roda dua dan roda tiga adalah sebagai berikut :

1. Kepemilikan Kedua $2 \%$

2. Kepemilikan Ketiga 2,5\%

3. Kepemilikan Keempat 3\%

4. Kepemilikan Kelima dan seterusnya 3,5\%

Sedangkan tarif pajak progresif untuk kendaraan bermotor roda empat atau lebih adalah sebagai berikut:

1. Kepemilikan Kedua 2,5\%

2. Kepemilikan Ketiga 3\%

3. Kepemilikan Keempat 3,5\%

4. Kepemilikan Kelima dan seterusnya $4 \%$

Berdasarkan undang-undang pemerintah daerah, khususnya asas desentralisasi pemerintah daerah memiliki sumber penerimaan yang terdiri atas hasil pajak daerah, hasil retribusi daerah, laba perusahaan daerah, dan pendapatan asli daerah yang sah.Salah satu sumber pendapatan asli daerah adalah dari sektor pajak kendaraan bermotor.

\section{METODE PENELITIAN \\ Pendekatan Penelitian}

Pendekatan penelitian menggunakan pendekatan deskriptif. Menurut Sugiyono (2010 : hal 29) pendekatan deskriptif merupakan pendekatan yang digunakan untuk menggambarkan atau menganalisis suatu hasil penelitian tetapi tidak digunakan untuk membuat kesimpulan yang lebih luas.

\section{Teknik Analisis Data}

Teknik analisis data yang digunakan dalam penelitian ini adalah dengan menggunakan metode deskriptif merupakan pendekatan yang digunakan untuk menggambarkan atau menganalisis suatu hasil penelitian tetapi tidak digunakan untuk membuat kesimpulan yang lebih luas(Sugiyono 2010:29). Langkah-langkah yang dilakukan dalam penelitian ini adalah sebagai berikut:

1. Melakukan survey ke instansi untuk memperoleh fakta-fakta dan data-data yang diperlukan berupa dokumentasi dan wawancara.

2. Mengumpulkan data yang berhubungan dengan penerapan tarif pajak progresif pada pajak kendaraan bermotor.

3. Melakukan tinjauan terhadap Undang-Undang atau Peraturan Daerah yang terkait dengan tarif pajak progresif.

4. Melakukan analisa data pembatyaran kendaraan bermotor yang diperoleh dari kantor UPT BP2RD PROVU Stabat. 


\section{PEMBAHASAN}

1. Penerapan Tarif Pajak Progresif pada Kendaraan Bermotor berdasarkan The Four Maxims

Pemungutan pajak progresif pada pajak kendaraan bermotor di Kota Stabat melalui UPT BP2RD PROVSU Stabat sudah sesuai dengan asas-asas pemungutan pajak. Asas-asas pemungutan pajak yang dekemukan oleh Adam Smith masih relevan untuk dapat diterapkan dan bisa menjadi acuan dalam perpajakan, yakni asas-asas tersebut antara lain adalah keadilan (equity), kepastian hukum(certainly), ketepatan waktu dalam membayar pajak (conveinence of payment), dan efisien (efficiency). Dengan didasari oleh asas-asas pemungutan pajak yang ada, hak dan kewajiban negara/pemerintah maupun masyarakat mempunyai posisi yang sama kuatnya dalam menentukan bagaimana sebaiknya pajak harus diterapkan dengan dasar undang-undang yang kuat, yaitu mengenai siapa yang akan dikenakan pajak, kapan akan dikenakan pajak, berapa jumlah pajak yang harus dibayar, sanksi yang akan dikenakan jika terlambat membayar dan lain sebagainya.

\section{Asas Equality ( asas keadilan)}

Asas equality yaitu pembebanan pajak harus sesuai dengan kemampuan wajib pajak. Berdasarkan asas ini penerapan pemberlakuan tarif pajak progresif bagi kepemilikan kendaraan bermotor lebih dari satu unit dapat dikategorikan sebagai kelompok masyarakat yang memiliki penghasilan lebih besar (lebih dari cukup), sehingga pemungutan pajaknya harus lebih banyak.

\section{Menghitung tarif pajak progresif pada Pajak Kendaraan Bermotor (PKB)}

Untuk menghitung pajak progresif pada Pajak Kendaraan Bermotor adalah sebagai berikut contoh

: Bunga memiliki 2 buah kendaraan bermotor. Kendaraan kepemilikan pertama adalah sepeda motor Yamaha dengan tipe 14D (All115C/Mio Soul) dengan tahun pembuatan 2012 adalah sebesar Rp. 11.000.000. Dan kendaran kepemilikan kedua adalah sepeda motor Honda dengan tipe XIB02N04L0 A/T / 108.2 tahun pembuatan 2016 adalah sebesar Rp. 10.900.000.

Untuk kepemilikan kendaraan bermotor pertama Bunga dikenakan pajak sebesar 1,75\% dan bobot sebesar 1 ( Pergub Sumatera Utara No. 37 tahun 2015).

Besarnya pokok $\mathrm{PKB}$ yang terutang adalah sebagai berikut:

$\mathrm{PKB}=$ Tarif $\mathrm{PKB} \times \mathrm{NJKB} \times$ Bobot

$\mathrm{PKB}=1,75 \% \times \mathrm{Rp} .11 .000 .000 \times 1$

$\mathrm{PKB}=1,75 \% \times \mathrm{Rp} .11 .000 .000$

$\mathrm{PKB}=\mathrm{Rp} .192 .500$

Untuk kepemilikan kendaraan bermotor kedua, Bunga dikenakan pajak progresif sebesar 2\% dan bobot sebesar 1 ( Pergub Sumatera Utara No. 37 tahun 2015). Sepeda motor kedua : Honda dengan tipe XIB02N04L0 A/T / 108.2 tahun pembuatan 2016.

$\mathrm{PKB}=$ Tarif $\mathrm{x}$ NJKB $\times$ Bobot

$\mathrm{PKB}=2 \% \times \mathrm{Rp} .10 .900 .000 \times 1$

$\mathrm{PKB}=2 \% \times \mathrm{Rp} .10 .900 .000$

$\mathrm{PKB}=$ Rp. 218.000

Perhitungan pajak progresif menurut UPT BP2RD PROVSU Stabat adalah sebagai berikut:

$\mathrm{PKB}=$ Tarif $\mathrm{PKB} \times \mathrm{NJKB}$

$\mathrm{PKB}=1,75 \%$ x Rp. 10.900 .000

$\mathrm{PKB}=\mathrm{Rp} .190 .750$

Kemudian,

$\mathrm{PKB}=0,25 \% \times$ Rp. 10.900 .000

$\mathrm{PKB}=$ Rp. 27.250

Pajak progresif yang harus dibayar Rp. $190.750+$ Rp. $27.250=$ Rp. 218.000 . 
Dari perhitungan diatas dapat disimpulkan walaupun berbeda dalam cara perhitungan tetapi hasil perhitungannya sama.

\section{Asas Certainly ( Asas Kepastian Hukum)}

Berdasarkan asas ini dasar pengenaan pajak, tarif pajak, objek pajak, subjek pajak sudah sangat jelas sehingga tidak ada kemungkinan bagi wajib pajak untuk tidak membayarkan kewajibannya. Dasar pengenaan pajak telah diatur dalam UU No. 28 Tahun 2009 Pasal 5 ayat (1). Berdasarkan UU tersebut, dasar pengenaan Pajak Kendaraan Bermotor adalah hasil perklaian dari 2 (dua) unsur pokok, yaitu nilai jual kendaraan bermotor dan bobot yang mencerminkan secara relatif tingkat kerusakan jalan dan pencemaran lingkungan akibat penggunaan kendaraan bermotor.

Objek pajak dijelaskan pada PERDA No. 1 Tahun 2011 Pasal 4 ayat (1). Berdasarkan PERDA tersebut yang termasuk objek pajak adalah kepemilikan atau penguasaan kendaraan bermotor, sebagaimana dimaksud adalah kendaraan bermotor beroda beserta gandengannya, yang dioperasikan disemua jenis jalan darat. Subjek pajak telah diatur dalam PERDA No. 1 Tahun 2011 Pasal 5 ayat (1). Berdasarkan PERDA tersebut, wajib pajak merupakan subjek pajak yang telah memenuhi persyaratan tertentu, yakni orang atau badan yang memiliki kendaraan bermotor. Berdasarkan asas ini BP2RD PROVSU Stabat telah melakukan pemungutan pajak sesuai dengan Peraturan Pemerintah yang ada dan telah dilaksanakan dengan baik.

\section{Asas Conveinance of payment (asas ketepatan waktu dalam membayar pajak)}

Asas Conveinance of payment yaitu pajak dipungut pada saat yang paling baik, dimana wajib pajak tidak keberatan atau kesulitan saat membayar tanggungan pajaknya. Pembayaran pajak kendaraan bermotor UPTD melaksanakan pemungutan pajak yaitu sesuai dengan tanggal mati pajak kendaraan bermotor.

Pajak kendaraan bemotor apabila sudah jatuh tempo masa berlaku STNK (Surat Tanda Nomor Kendaraan) belum melakukan perpanjangan, maka akan dikenakan denda. Denda yang dikenakan yaitu denda atas PKB (Pajak Kendaraan Bermotor ) dan SWDKLLJ (Sumbangan Wajib Dana Kecelakaan Lalu Lintas Jalan). Untuk perhitungan SWDKLLJ dilakukan oleh Jasa Raharja.

\section{Perhitungan Denda PKB}

Contoh : Adi memiliki kendaran bermotor roda dua berupa sepeda motor dan terlambat membayarkan pajak kendaraan bermotornya selama 6 bulan. Total pajak kendaraan bermotor sebesar Rp. 170.000, maka perhitungannya adalah sebagai berikut :

Jumlah PKB x Tarif Denda x lamanya denda

Rp. $170.000 \times 25 \%$ x 6/12 = Rp. 21.250

Besarnya denda Pajak Kendaraan Bermotor yang harus di bayar Adi adalah Rp. 21.250

\section{Asas Efficiency (Asas Efisien)}

Berdasarkan asas efisiensi, pengenaan tarif pajak progresif pada kendaraan bermotor melalui pelayanan pemungutan pajak dan informasi pemungutan pajak sangat jelas dan cukup baik, UPT BP2RD PROVSU Stabat melakukan sosialisasi ke masyarakat melalui camat atau lurah dengan menggunakan fasilitas-fasilitas yang ada dan berusaha untuk mencapai target pendapatan pajak melebihi target yang telah ditetapkan.

Tabel 1. Target dan realisasi penerimaan Pajak Kendaraan Bermotor di UPT BP2RD PROVSU Stabat

\begin{tabular}{|c|c|c|c|c|}
\hline No & $\begin{array}{c}\text { Tahun } \\
\text { Penerimaan }\end{array}$ & Target Tahun Anggaran & Realisasi Penerimaan & Persentase \\
\hline 1 & 2013 & $\begin{array}{ll}\mathrm{Rp} & 15.585 .092 .168\end{array}$ & $\begin{array}{ll}\mathrm{Rp} & 16.222 .956 .684\end{array}$ & $104 \%$ \\
\hline 2 & 2014 & $\begin{array}{ll}\mathrm{Rp} & 17.139 .994 .340\end{array}$ & Rp 19.877 .166 .264 & $116 \%$ \\
\hline
\end{tabular}


Analisis Tarif Pajak Progresif Kendaraan Bermotor Berdasarkan The Four Maxims Di Upt Bp2rd Provsu Stabat

\begin{tabular}{|c|c|r|r|c|c|}
3 & 2015 & $\mathrm{Rp} 20.413 .344 .941$ & $\mathrm{Rp} 25.508 .703 .210$ & $125 \%$ \\
\hline 4 & 2016 & $\mathrm{Rp} 27.410 .671 .610$ & $\mathrm{Rp} 31.920 .175 .707$ & $116 \%$ \\
\hline 5 & 2017 & $\mathrm{Rp} 33.198 .923 .477$ & $\mathrm{Rp} 29.327 .003 .444$ & $88 \%$ \\
\hline \multicolumn{2}{|l|}{ Jumlah } & $\mathrm{Rp} \mathrm{113.748.026.536}$ & $\mathrm{Rp} 122.856 .005 .309$ & $108 \%$ \\
\hline
\end{tabular}

Sumber: (diolah oleh penulis)

Berdasarkan tabel 1. menunjukkan jumlah penerimaan pajak kendaraan bermotor pada tahun 2013 sebesar 104\%, menunjukkan telah melebihi target yang telah ditetapkan. Pada tahun 2014 sebesar 116\% telah melebihi target yang telah ditetapkan. Pada tahun 2015 penerimaan pajak kendaraan bermotor mengalami peningkatan sebesar 125\% dan telah melebihi target yang telah ditetapkan. Pada tahun 2016 sebesar 116\% dan telah melebihi target. Pada tahun 2017 penerimaan pajak kendaraan bermotor tidak mencapai target hanya sebesar $88 \%$. Hal ini disebabkan oleh tingginya mutasi kendaraan keluar daerah, dan faktor ekonomi global sehingga berkurangnya daya beli masyarakat akan kendaraan bermotor.

\section{Upaya yang dilakukan oleh Petugas BP2RD PROVSU Stabat dalam meningkatkan penerimaan Pajak Kendaraan Bermotor.}

Pajak kendaraan bermotor merupakan salah satu primadona bagi pembiayaan pembangunan di daerah. Pajak kendaraan bermotor merupakan pungutan yang dilakukan oleh Pemerintah Provinsi Sumatera Utara dan merupakan salah satu sumber pendapatan daerah. Mengingat penerimaan pajak kendaraan bermotor sangat diandalkan untuk menunjang Pendapatan Asli Daerah (PAD), maka sumber penerimaan tersebut perlu dioptimalkan. Upaya yang dilakukan oleh petugas UPT B2RD PROVSU Stabat adalah dengan cara menyediakan fasilitas berupa Bus SAMSAT Keliling untuk menjangkau wajib pajak yang berada didaerah yang cukup jauh dari lokasi SAMSAT. Pihak UPT BP2RD PROVSU Stabat melakukan sensus dengan cara melakukan sosialisasi ke masyarakat melalui camat atau lurah agar wajib pajak mempunyai kesadaran untuk membayarkan kewajibannya.

\section{KESIMPULAN, SARAN DAN BATASAN PENELITIAN}

\section{Kesimpulan}

Berdasarkan uraian dari hasil penelitian dan pembahasan yang telah dikemukaan, maka dapat ditarik kesimpulan sebagai berikut:

1. Berdasarkan asas equality (asas keadilan), pengenaan tarif pajak progresif pada Pajak Kendaraan Bermotor sangatlah adil karena pembebanan pajak harus sesuai dengan kemampuan wajib pajak sehingga tidak dapat dikatakan bahwa wajib pajak tidak mampu membayar kewajiban perpajakannya.

2. Berdasarkan asas certainly (asas kepastian hukum), dasar pengenaan Pajak Kendaraan Bermotor sangatlah jelas, pengenaan tarif pajak progresif pada pajak kendaraan bermotor dipungut berdasarkan Peraturan Gubernur Sumatera Utara No. 37 Tahun 2015 tentang Pelaksanaan Pemungutan Pajak Kendaraan Bermotor dan Bea Balik Nama Kendaraan Bermotor Di Provinsi Sumatera Utara.

3. Berdasarkan asas Conveinance of payment (asas ketepatan waktu dalam membayar pajak), untuk pembayaran pajak kendaraan bermotor UPTD melaksanakan pemungutan pajak yaitu sesuai dengan tanggal mati pajak kendaraan bernotor atau saat dimana wajib pajak menerima penghasilan

4. Berdasarkan asas efisiensi, pengenaan tarif pajak progresif pada kendaraan bermotor melalui pelayanan pemungutan pajak dan informasi pemungutan pajak yang sangat jelas dan cukup baik, UPT BP2RD PROVSU Stabat berusaha terjun langsung ke masyarakat melalui camat atau lurah dengan menggunakan fasilitas-fasilitas yang ada dan berusaha untuk mencapai pendapatan pajak melebihi target yang telah ditetapkan

5. Upaya yang dilakukan oleh petugas UPT B2RD PROVSU Stabat adalah dengan cara menyediakan fasilitas berupa Bus SAMSAT Keliling untuk menjangkau wajib pajak yang berada didaerah yang cukup jauh dari lokasi SAMSAT 


\section{Saran}

1. UPT BP2RD PROVSU Stabat sebaiknya lebih meningkatkan lagi penerimaan Pajak Kendaraan Bermotor, agar ditahun-tahun berikutnya penerimaan pajak kendaraan bermotor mampu mencapai target yang lebih tinggi.

2. Pemerintah Daerah Sumateera Utara harus memperhatikan penerimaan pajak progresif agar mampu mengoptimalkan peneriman Pendapatan Asli daerah. Tidak hanya dari sektor PKB dan BBNKB saja yang memberikan kontribusi tinggi.

3. Untuk mempermudah dan mempercepat wajib pajak dalam membayar pajak sebaiknya pihak kantor UPT BP2RD PROVSU Stabat dapat menambah fasilitas pelayanan seperti SAMSAT Corner yang dibuka di luar kantor dan SAMSAT Drive Thru untuk mempermudah proses pelayanan yang ada.

\section{Batasan Penelitian}

Penelitian ini dibatasi hanya melakukan analisis penerapan tarif pajak progresif pada pajak kendaraan bermotor berdasarkan The Four Maxims Di UPT BP2RD PROVSU Stabat. Periode penelitian ini menggunakan 5 tahun mulai tahun 2013 sampai dengan 2017.

\section{DAFTAR PUSTAKA}

Darmadi, Hamid (2014). Metode Penelitian Pendidikan dan Sosial. ALFABETA. Bandung

Diana Sari (2013). Konsep Dasar Perpajakan. Refika Aditama. Bandung

Dinda Rezki Giovani (2014). Faktor-Faktor Yang Mempengaruhi Penerimaan Pajak Kendaraan

Bermotor Di Provinsi Jawa Timur. Jurnal Ilmu Dan Riset Akuntasi, Sekolah Tinggi Ilmu Ekonomi Indonesia Surabaya. Vol. 3 No. 12.

Fajarani (2013). Pengenaan Tarif Pajak Progresif Pada Kendaraan Bermotor Berdasarkan The Four Maxims. Jurnal Vol 1 No 2 Universitas Surabaya. Surabaya. http://php/jurnalakuntansi/article/view/739/baca-artikel. Diakses 28 Desember 2017

Kuncoro, Mudrajad, 2009, Metode Riset untuk bisnis dan Ekonomi. Bagaimana Meneliti dan Menulis Tesis? (Edisi 3). Erlangga, Jakarta.

Mardiasmo. 2011. Perpajakan. Edisi Revisi 2011, ANDI, Yogyakarta.

Mardiasmo. 2016. Perpajakan. Edisi Terbaru 2016, ANDI, Yogyakarta.

Mokoginta, Nani Chairani (2015). "Analisis Efektivitas Pemungutan Pajak Kendaraan Bermotor Dan Bea Balik Nama Kendaraan Bermotor Dalam Peningkatan PAD Provinsi Sulawesi Utara". Fakultas Ekonomi dan Bisnis, Jurusan Akuntansi, Universitas Sam Ratulangi Manado, Jurnal Vol 3 No 1 Maret 2015. Provinsi Sulawesi Utara

Moningka, Novita Asrila,dkk. 2015. "Analisis Pengenaan Tarif Pajak Progresif Pada Pajak Knedaraan Bermotor Berdasarkan The Four Maxims". Jurnal Vol 1 No 3. Universitas Sam Ratulangi Manado. Provinsi Sulawesi Utara. https://ejournal.unsrat.ac.id/index.php/gc/article/view/8443 Diakses 28 Desember 2017

Nugraha,Harist Agung. 2012. Penerapan Pajak Progresif Terhadap Wajib Pajak Kendaraan Bermotor Berdasarkan Peraturan Daerah Jawa Timur Nomor 9 Tahun 2010 (Studi di Kantor Bersama SAMSAT Kota Malang). Skripsi. Universitas Brawijaya. Malang http://hukum.studentjournal.ub.ac.id/index.php/hukum/article/view/301/303 $\quad$ Diakses 28 Desember 2017

Peraturan Menteri Dalam Negeri Republik Indonesia Nomor 101 Tahun 2014 Tentang Perhitungan Dasar Pengenaan Pajak Kendaraan Bermotor dan Bea Balik Nama Kendaraan Bermotor, Jakarta.

Peraturan Gubernur Sumatera Utara Nomor 21 Tahun 2011 Tentang Petunjuk Pelaksanaan Pemungutan Pajak Kendaraan Bermotor dan Bea Balik Nama Kendaraan Bermotor Provinsi Sumatera Utara, Provinsi Sumatera Utara. 
Peraturan Gubernur Sumatera Utara Nomor 37 Tahun 2015 Tentang Pelaksanaan Pemungutan Pajak Kendaraan Bermotor dan Bea Balik Nama Kendaraan Bermotor di Provinsi Sumatera Utara, Provinsi Sumatera Utara.

Peraturan Gubernur Sumatera Utara Nomor 11 Tahun 2014 Tentang Perhitungan Dasar Pengenaan Pajak Kendaraan Bermotor dan Bea Balik Nama Kendaraan Bermotor, Provinsi Sumatera Utara.

Peraturan Daerah Nomor 1 Tahun 2011 Tentang Pajak Daerah Provinsi Sumatera Utara sebagaimana telah diubah dengan Peraturan Daerah Nomor 1 Tahun 2015 Tentang Perubahan atas Peraturan Daerah Nomor 1 Tahun 2011 Tentang Pajak Provinsi Sumatera Utara, Provinsi Sumatera Utara.

Ramadhani,Amalia. (2017). Analisis Pengenaan Tarif Pajak Progresif Dalam Peningkatan Pendapatan Asli Daerah Pada Kendaraan Bermotor Di SAMSAT Medan Selatan. Skripsi. Universitas Muhammadiyah Sumatera Utara

rogresif kepada wajib pajak agar wajib pajak mengetahui dan melakukan pembayaran atas Sugiyono. 2010. Metode Penelitian Kualitatif, Kuantitatif dan R\&D. ALFABET. Bandung

Undang-undang Republik Indonesia Nomor 28 Tentang Pajak Daerah dan Retribusi Daerah, Jakarta.

Waluyo, 2013,Perpajakan Indonesia, Edisi Sebelas, Salemba Empat, Jakarta. 